\title{
O território e a intervenção profissional frente à violência enquanto uma expressão da questão social
}

\author{
The territory and the professional intervention against violence as an expression of the \\ social question
}

\author{
Alicia Santolini Tonon * \\ Vera Lucia Tieko Suguihiro **
}

\begin{abstract}
Resumo:
O presente trabalho tem por objetivo discutir, ainda que brevemente, sobre o tema "território" enquanto aspecto de relevância junto ao enfrentamento das expressões da questão social - aqui sendo destacada a violência contra crianças e adolescentes de modo a assegurar o envolvimento das políticas sociais e dos órgãos de proteção e garantias de direitos, a partir da instauração de uma rede de proteção, o que supõe conhecer os riscos, as vulnerabilidades sociais a que estão sujeitos, bem como os recursos que contam para enfrentar tais situações com menor dano pessoal e social possível; para que a partir do que é evidenciado nas particularidades de cada território se possa formular ações que venham ao encontro das necessidades concreta da população alvo.
\end{abstract}

Palavras-chave: Criança; Adolescente; Território; Violência; Questão social.

\begin{abstract}
:
This paper aims to discuss, albeit briefly, on "territory" as an aspect of coping with the extreme relevance of expressions of social issues - here being highlighted violence against children and adolescents - to ensure the involvement of social policies and protection agencies and warranty rights from the establishment of a safety net, which means knowing the risks, vulnerabilities that are subject to social, as well as the features that count in tackling such situations with less personal injury and possible social, so that, from what is shown in the particularities of each territory is to formulate actions that come from meeting with the concrete reality of the target population.
\end{abstract}

Keywords: Children; Adolescents; Territory; Violence; Social issue.

\section{Introdução}

\footnotetext{
* Graduada em Serviço Social na Faculdades Integradas Antônio Eufrásio de Toledo, de Presidente Prudente e mestranda do curso de Mestrado Serviço Social e Políticas Sociais, da Universidade Estadual de Londrina-PR. Email: henrique.dat@hotmail.com

** Doutora em Serviço Social e Política Social pela PUC/SP. Professora do Curso de Graduação e do Programa de Pós-Graduação em Serviço Social e Políticas Sociais da Universidade Estadual de Londrina e membro do Núcleo de Gestão em Política Social da UEL. E-mail: suguihiro@uel.br
} 
Ao tratarmos da violência enquanto fenômeno que se expressa nas relações societárias, faz-se necessária a sua compreensão mediante o contexto no qual se encontra inserida, ou seja, as configurações que envolvem tal fenômeno e as implicações do contexto sócio-histórico neste processo.

Dessa forma, coloca-se enquanto lócus de discussão o conceito de questão social, bem como sua constituição diante da sociedade capitalista, de modo a referenciar a violência enquanto uma de suas expressões, em que podemos elencar, entre várias questões, a saúde, a habitação, a urbanização, a política, o gênero, a cultura, a precarização dos serviços. Neste trabalho, situamos a questão da violência, que se coloca como um fenômeno de relações de desigualdade a partir da exploração e da força. Aqui, especificamente, tratamos da violência contra crianças e adolescentes que, além da relação de desigualdade, expressa também a relação de poder/força numa negação do valor de liberdade.

A violência assim como qualquer outra expressão nos mostra o quanto ainda precisamos avançar em relação aos direitos e igualdades sociais, diante de uma ordem vigente capitalista que, na busca pela obtenção de lucros, perde de vista os valores de seres humanos portadores de direitos para a personificação do capital e do trabalho, isto é, portadores de determinados caracteres sociais que o processo social de produção imprime aos indivíduos sociais (IAMAMOTO, 2004).

Neste sentido, ao inserir a violência diante da realidade que se manifesta, evidenciamos o território como parte deste processo. É a partir dele que percebemos sua relevância ao permitir que se conheçam as relações e os valores expressos, que se diferenciam de comunidade a comunidade. Assim, o território se mostra como um espaço passível de intervenção, na medida em que se coloca como parte constituinte do processo de rede e de organização na busca por transformações.

O princípio da territorialização significa reconhecer a presença de múltiplos fatores sociais e econômicos que levam a família e o indivíduo de uma determinada área a uma situação de vulnerabilidade, risco pessoal e social. Este princípio orienta as ações e políticas na perspectiva do alcance da universalidade de cobertura entre indivíduos e famílias, no planejamento da localização da rede de serviços, a partir dos territórios de maior incidência de vulnerabilidades e riscos. 
Sendo assim, a partir deste trabalho, podemos adentrar a uma reflexão crítica sobre as questões que se fazem presentes diante da sociedade vigente e suas expressões, assim como a configuração do território, à medida que evidenciamos a violência como um fenômeno que se expressa nesses espaços, bem como pensar práticas a partir das reais necessidades da população, abrangendo este espaço como coparticipante do Sistema de Garantia de Direitos.

\section{Formação histórica da questão social no Brasil}

A história da sociedade brasileira esta permeada de situações nas quais aspectos importantes da questão social estão presentes, revelando disparidades econômicas, políticas e culturais, envolvendo classes sociais e as desigualdades existentes nesta relação. Ao longo das várias repúblicas formadas desde a abolição da escravatura e o fim da monarquia, a questão social passou a ser elemento essencial das formas e movimentos da sociedade - não que já não existisse nessas épocas, porém de forma aberta sem qualquer possibilidade de negociação - em que as diversidades e os antagonismos passam a ser enfrentado como situações suscetíveis de debate, controle, mudança, solução ou negociação (IANNI, 1992).

Para Wanderley (2000) discernir a questão social na América Latina exige atentar as particularidades histórico-culturais das relações sociais, nas suas dimensões econômicas, políticas, culturais com destaque na concentração de renda e poder e na pobreza das grandes maiorias. Ainda:

[...] se põe no espaço e no tempo, diferentemente da realidade europeia, na instituição da nacionalidade, da esfera estatal, da cidadania, da implantação do capitalismo. Em consequência, deverá ser entendida e datada de modo distinto (WANDERLEY, 2000, p. 61).

Compreendemos assim que a gênese da questão social na sociedade burguesa deriva do caráter coletivo da produção contraposto a apropriação privada da própria atividade humana. As configurações assumidas pela questão social integram tanto determinantes históricos objetivos quanto dimensões subjetivas, fruto da ação dos sujeitos na construção da história. Ela expressa, portanto, uma arena de lutas políticas e culturais na disputa entre 
projetos societários, informados por distintos interesses de classes na condução das políticas econômicas e sociais, que trazem o selo das particularidades históricas (IAMAMOTO, 2011).

Nesse terreno contraditório entre a lógica do capital e a lógica do trabalho, a questão social representa não só as desigualdades, mas, também, o processo de resistência e luta dos trabalhadores. Por isto ela é uma categoria que reflete a luta dos trabalhadores, da população excluída e subalternizada, na luta pelos seus direitos econômicos, sociais, políticos e culturais. E é aí, também, que residem as transformações históricas da concepção de questão social. O avanço das organizações dos trabalhadores e das populações subalternizadas coloca em novos patamares a concepção de questão social.

Aos poucos, alguns setores dominantes e os governos são levados a reconhecer que a questão social é uma realidade, tanto que na década de 1920 e 1930 começam a admitir que a questão social pudesse deixar de ser considerada problema de polícia, tratando-a como um problema político, porém marcado por retrocessos, já que nunca deixou de ocorrer repressão quanto as possíveis reivindicações.

Tratar da questão social nas particularidades brasileiras supõe reconhecer que a transição do capitalismo competitivo ao monopolista foi marcada por uma forma de dominação burguesa, que Fernandes (1975) qualifica de "democracia restrita", como clara dissociação entre desenvolvimento capitalista e regime político democrático. Sendo assim, o papel do Estado foi imprescindível em garantir que se preservasse a ordem, evitando qualquer pressão popular, a partir do recurso repressivo e a intervenção econômica a favor dos interesses dos dominantes (COUTINHO, 2000).

Neste sentido, o Estado ainda produz efeitos sobre o conjunto das classes trabalhadoras, em que o trabalhador aparece como um mero vendedor de mercadorias, que vende sua força de trabalho para a satisfação de suas necessidades vitais, e seu trabalho assume a determinação social de trabalho assalariado; e do processo de acumulação no qual a partir da mais valia em que a tendência é reduzir ao mínimo o custo da produção e intensificar a força produtiva, ou seja, o conjunto dos meios de produção convertido em capital, monopolizado por uma parte da sociedade (IAMAMOTO, 2004). Isto é, a apropriação de uma classe pela outra no processo de acumulação capitalista, visando cada vez mais a obtenção de lucro e o crescimento econômico, mesmo que para isso as 
consequências sejam desastrosas para a grande maioria da população, como bem são lembradas por Jaguaribe (1986, p. 187):

\begin{abstract}
A sociedade brasileira se caracteriza pela maior discrepância existente no mundo entre seus indicadores econômicos e seus indicadores sociais. A característica fundamental da sociedade brasileira é seu profundo dualismo, em que de um lado encontra-se uma moderna sociedade industrial, e de outro, encontra-se uma sociedade primitiva, vivendo em nível de subsistência.
\end{abstract}

Vista assim, a sociedade em movimento se apresenta como uma vasta "fábrica" das desigualdades e antagonismos que constituem a questão social.

Em síntese, o crescimento da força de trabalho disponível é impulsionado pelas mesmas causas que a força expansiva do capital, expressando a lei geral da acumulação capitalista. Esta é modificada em sua realização pelas mais variadas circunstâncias, fruto do aperfeiçoamento dos meios de produção e do desenvolvimento da produtividade do trabalho social mais rápido do que população trabalhadora produtiva. Gera, assim, uma acumulação da miséria relativa à acumulação do capital, encontrando-se aí a raiz da produção/reprodução da questão social na sociedade capitalista (IAMAMOTO, 2004).

Nesta perspectiva, a questão social diz respeito ao conjunto das expressões das desigualdades sociais engendradas na sociedade capitalista madura, impensáveis, sem a intermediação do Estado. Tem sua gênese no caráter coletivo da produção, contraposto à apropriação privada da própria atividade humana - o trabalho - das condições necessárias a sua realização, assim como de seus frutos. A questão social expressa, portanto, disparidades econômicas, políticas e culturais das classes sociais, colocando em causa as relações entre amplos segmentos da sociedade civil e o poder estatal (IAMAMOTO, 2004).

\title{
Questão social na contemporaneidade
}

Considerada expressão das desigualdades inerentes ao processo de acumulação e dos efeitos que produz sobre o conjunto das classes trabalhadoras e sua organização, a questão social não é um fenômeno recente, típico do esgotamento dos chamados trinta anos gloriosos da expansão capitalista. Trata-se ao contrário de uma "velha questão social" inscrita na própria natureza das relações sociais capitalistas, mas que, na contemporaneidade, reproduz-se, sob novas mediações históricas, em que evidencia a 
imensa fratura entre o desenvolvimento das forças produtivas de trabalho e as relações sociais que o sustentam. Fratura esta que vem traduzindo a "violência escondida" nas relações que permeiam o capital. Violência que tem o aparato repressivo do Estado a serviço da propriedade e do poder dos que a dominam (IAMAMOTO, 2011).

Discutir a questão social significa um modo de problematizar os dilemas existentes na sociedade contemporânea: como a crise do modelo conhecido como Welfare State, que reabre o problema da justiça social, redefine o papel do Estado e o sentido da mesma responsabilidade pública.

Para colocar nos termos de Castel (1995, p. 114):

\begin{abstract}
A questão social é a aporia das sociedades modernas que põe em foco a disjunção, sempre renovada, entre a lógica do mercado e a dinâmica societária, entre a exigência ética dos direitos e os imperativos de eficácia da economia, entre a ordem legal que promete igualdade e a realidade das desigualdades e exclusões tramada na dinâmica das relações de poder e dominação.
\end{abstract}

Hoje sabemos que os tempos são outros, em que as lutas e conquistas do passado estão sendo devastadas pela avalanche neoliberal, que a destituição dos direitos também significa a erosão das mediações políticas entre o mundo do trabalho e as esferas públicas, sendo o Estado voltado para as exigências neoliberais, capitalistas e os direitos sociais cada vez mais fragilizados, diante dessa óptica mercantilista que nos permite assim avaliar o sentido devastador da desmontagem das esferas públicas de ação e representação.

No atual perfil assumido pela questão social, encontram-se as políticas governamentais favorecedoras da esfera financeira e do grande capital produtivo que capturam o Estado, as empresas nacionais, as classes e grupos sociais que passam a assumir o ônus das exigências do mercado. Nesta perspectiva, a questão social é mais do que as expressões da pobreza, miséria e exclusão, ela condensa a banalização do humano que atesta a radicalidade da alienação e invisibilidade do trabalho social e dos sujeitos que o realizam, marcando a relação indissolúvel entre trabalho e questão social, como destaca lanni (1992), o trabalho encontra-se no centro da questão social, tanto as formas de trabalho quanto a apologia do trabalho, ou seja, sua louvação ou beatificação expressa na ética do trabalho. Assim, a obtenção do intercâmbio de mercadorias, cujo controle é inteiramente alheio aos indivíduos produtores (IAMAMOTO, 2011). 
$\mathrm{Na}$ atual sociedade, sob a lógica capitalista, as manifestações da questão social tornam-se objeto de ações filantrópicas e de "programas focalizados de combate à pobreza", que acompanham a mais ampla privatização da política social pública, ou seja, a institucionalização da cidadania pela clivagem entre aqueles que têm acesso aos serviços fornecidos pelo mercado e aqueles que são destinados aos precários serviços públicos estatais (TELLES, 1996).

A questão social expressa, portanto, desigualdades econômicas, políticas e culturais das classes sociais, colocando em causa amplos segmentos da sociedade civil no acesso aos bens da civilização. Dispondo de uma dimensão estrutural, ela atinge visceralmente a vida dos sujeitos numa luta aberta e surda pela cidadania (IANNI, 1992), no embate pelo respeito aos direitos civis, sociais e políticos e aos direitos humanos.

Dessa forma, é que a questão social se coloca presente nos mais variados contextos, e suas expressões, diante das relações estabelecidas da ordem societária vigente, multiplicam-se. Neste sentido, a violência se evidencia como uma das formas mais perversas de relacionamento entre os homens e expressa muito claramente tal desigualdade.

Sendo assim é que podemos perceber a ligação direta de poder e mando, não só a partir das relações de produção, em que uma classe sobressai à outra, mas nas relações cotidianas nas quais o poder e a força prevalecem sobre o que se encontra em uma situação mais desigual. De modo a compreender melhor esta reflexão é que abordaremos no próximo capítulo tal conceito.

\section{Questão social e suas expressões: a violência e suas diferentes formas de manifestação}

A violência, enquanto uma expressão da questão social, expressa diretamente padrões de sociabilidade, modos de vida, modelos atualizados de comportamento vigentes em uma sociedade, em um momento determinado de seu processo histórico, a partir das diferentes configurações e relações existentes. Dessa forma, a violência se mostra presente nas relações interpessoais que se verificam entre homens e mulheres, entre adultos e crianças, como diz Adorno (apud AZEVEDO; GUERRA, 2001, p. 31), "[...] a violência é uma forma de relação social; esta inexoravelmente atada ao modo pelo qual os homens 
produzem e reproduzem suas condições de existência". Assim como nos coloca Teles e Melo (2003, p. 15):

[...] quer dizer uso da força física, psicológica ou intelectual para obrigar outra pessoa a fazer algo que não está com vontade; é constranger, é tolher a liberdade, é incomodar, é impedir a outra pessoa de manifestar seu desejo e sua vontade, sob pena de viver gravemente ameaçada ou até mesmo ser espancada, lesionada ou morta. É um meio de coagir, de submeter outrem ao seu domínio, é uma violação dos direitos essenciais do ser humano.

A violência é simultaneamente a negação de valores considerados universais, como a liberdade, a igualdade e a vida. Seu resultado mais visível é a conversão de sujeitos em objeto, sua coisificação. Enquanto manifestação de sujeição e de coisificação a violência só pode atentar contra a possibilidade de construção de sociedade de homens livres.

No cotidiano, a violência se apresenta como uma articulação das relações de desigualdade a partir da exploração e de forças. Esta violência se manifesta, concretamente, uma relação de poder que é exercido pelo adulto ou mesmo não adulto, porém mais forte, sobre a criança e o adolescente, sobre a mulher, sobre o idoso, ou seja, sobre aquele considerado mais fraco em relação ao outro, num processo de apropriação e dominação. Esse uso abusivo do poder da força é, de fato, uma profunda ruptura de uma relação de poder legitimado pelo direito e pelo diálogo, pela autoridade.

Partindo deste princípio, elucidamos a violência contra crianças e adolescentes que se mostra como uma transgressão do poder disciplinador do adulto, numa dinâmica de ensino/aprendizagem, em que se utiliza da sua diferença de idade e de poder/força numa negação do valor de liberdade, num processo de vitimização, submetendo-os ao poder do adulto como forma de coagi-los a satisfazer suas vontades e interesses, negando qualquer perspectiva da criança e do adolescente frente aos seus direitos, assim como aponta o Estatuto da Criança e do Adolescente:

Artigo 5 - Nenhuma criança ou adolescente será objeto de qualquer forma de negligência, discriminação, exploração, violência, crueldade e opressão, punido na forma da lei qualquer atentado, por omissão, aos seus direitos fundamentais (BRASIL, 1990). 
A violência ainda pode ser entendida como um fenômeno que se configura de diferentes formas, demonstrando para tanto conceitos específicos de acordo com sua forma de expressão, como a violência interpessoal, que ocorre na interação entre as pessoas, sendo normalmente em relação àquelas que demonstram dificuldade de resolver conflitos por meio da conversa, como também nas relações entre pais e filhos, homens e mulheres, irmãos, entre outras, nas quais estão caracterizadas as relações de poder (MINAYO, 1994). É dividida em violência intrafamiliar e comunitária.

A violência intrafamiliar ocorre nas relações familiares de modo que qualquer ação ou omissão de um membro da família venha a prejudicar a integridade física, psicológica ou até mesmo os direitos do outro. Nesta forma de violência podemos observar a agressividade como forma justificada pela família como um método de educar e até mesmo nas relações entre irmãos, que perante a sociedade parece algo aceito, mas que pode sinalizar o tipo de comportamento que a criança ou adolescente apresenta dentro e fora de casa. Quando se identifica que uma criança ou adolescente vem sofrendo violência dentro de casa é bem provável que outras pessoas também sofram, sendo comum a existência de xingamentos, humilhações e agressões físicas entre eles.

Já a violência comunitária pode ser diferenciada por não ocorrer entre membros familiares, ela ocorre entre pessoas que não possuem laços de parentesco, conhecidos ou desconhecidos, podendo ser manifestada por atos de violência física e/ou sexual. Também podemos destacar neste conceito as violências ocorridas dentro das instituições públicas ou privadas como: escolas, serviços de saúde, comunidades, projetos sociais, entre outros (MINAYO, 1994).

As relações estabelecidas entre os adultos com crianças e adolescentes, conforme coloca Azevedo e Guerra (1989), são hierárquicas, adultocêntricas, firmadas no poder do adulto sobre a criança. A vitimização pressupõe o abuso, como sendo a ação de um adulto, capaz de causar dano físico ou psicológico à criança, fazendo dela sua cúmplice e estabelecendo com ela um pacto de silêncio. Por isso, considera-se o abuso-vitimização como estando ligado à mesma forma de violência. Diante disso, partimos da compreensão do que a violência doméstica é:

Todo ato ou omissão praticado por pais, parentes ou responsáveis, contra crianças e adolescentes que - sendo capaz de causar dano físico, sexual e/ou 
psicológico à vítima - implica de um lado uma transgressão do poder/dever de proteção do adulto e, de outro, uma coisificação da infância, isto é, uma negação do direito que crianças e adolescentes têm de serem tratados como sujeitos e pessoas em condição peculiar de desenvolvimento (GUERRA, 1998, p. 32).

A violência física é definida por Guerra (1998, p. 177) como "toda ação que causa dor física numa criança, desde um simples tapa até o espancamento fatal representam um só continuum de violência". Violência esta que normalmente se dá em uma relação de poder em relação à outra pessoa, por meio de agressões físicas.

A violência psicológica pode ser entendida como toda ação ou omissão que venha a causar dano à autoestima, à formação da identidade, à integridade ou ao desenvolvimento emocional e cognitivo da criança ou do adolescente, manifestando-se como forma de rejeição, discriminação, desrespeito e humilhações (BRASIL, 2004).

A violência sexual pode ser entendida como expõe Azevedo e Guerra (1998, p. 177):

Configura-se como todo ato ou jogo sexual, relação hetero ou homossexual, entre um ou mais adultos e uma criança ou adolescente, tendo por finalidade estimular sexualmente a criança ou adolescente ou utilizá-los para obter uma estimulação sexual sobre sua pessoa ou de outra pessoa).

A negligência representa uma omissão no que se refere a prover as necessidades de uma criança ou adolescente, podendo ser definida:

O abandono material e moral, a omissão ou a negligência dos pais, da sociedade e do Estado são as primeiras formas de lesão e/ou violação dos iniciais direitos de qualquer recém-nascido. É a partir delas que se projetam as demais, uma vez que à medida que a criança aumenta sua idade, ao lado das tímidas e insuficientes ações governamentais, diversificam-se, de forma crescente, as ações e os mecanismos de lesão dos novos direitos (SOUZA, 2008, p. 75).

A exploração sexual comercial compreende o abuso sexual e a remuneração em espécie à criança ou adolescente, numa relação de mercadorização para satisfazer a necessidade de outro. Esta diretamente relacionada à rede familiar fragilizada pela pobreza, assim como por fatores como o desemprego, violência, que deixam a família exposta a uma situação de vulnerabilidade social ${ }^{1}$, em que esta forma de violência acaba

\footnotetext{
1 Podendo ser entendidos como ausência ou precariedade de renda; o desemprego e o trabalho informal e inseguro; o acesso frágil ou inexistente aos serviços sociais públicos; a perda ou fragilização de vínculos de
} 
por ser um método na busca de auferir o lucro a partir do comércio de seu próprio corpo. A pobreza, não pode ser vista como determinante da violência existe também imbricado nesta relação à questão social, política, econômica, cultural, ideológica, porém nas suas implicações como a falta de comida, habitação, escola, proteção, ou seja, sem a garantia dos mínimos sociais, acaba por condicionar grande número de crianças e adolescentes a esta situação (GUERRA, 1998).

Cabe lembrar que uma criança ou um adolescente pode ser vítima de mais de um tipo de violência, porque muitas dessas situações se relacionam na maioria das vezes a outra, como, por exemplo, a violência física que vem seguida de xingamentos e humilhações, assim como a sexual de ameaças e torturas psicológicas.

A violência ocorrida na fase da infância e da adolescência causa danos que podem ser levados para toda a vida, influenciando nas suas escolhas e ainda podendo se perpetuar pela reprodução da violência com as gerações futuras, pois nesta fase de desenvolvimento tanto físico quanto emocional é que a criança e o adolescente estão absorvendo os valores básicos, na forma de conceitos morais e éticos determinantes para sua formação (SOUZA, 2008).

Nesse sentido de superação desta situação de violência vivenciada por crianças e adolescentes é que nos deparamos com a necessidade de um trabalho articulado com as redes de proteção a partir do território em que vivem, já que este se mostra como um elemento de extrema importância quando tratamos de rede de proteção, pois nos coloca na relação concreta, partindo daquilo que é vivenciado pelas famílias e indivíduos no seu cotidiano, permitindo-nos a observação e compreensão das suas relações.

\section{A violência e o território enquanto espaço de enfrentamento}

A situação de risco pessoal e social, pela violação de direitos deve ser compreendida no contexto sócio-histórico, econômico, político e cultural que exerce a influência e provoca o surgimento de situações de risco ao qual a criança, o adolescente e suas famílias são expostos - aqui sendo destacada a violência. Assim, tais influências possuem significados diferentes, expressos de acordo com o território onde se encontram, daí a 
relevância de se compreender como as relações se estabelecem e propor ações que venham ao encontro com a realidade da população, assim como afirma Milton Santos (2007, p. 141):

\begin{abstract}
Uma política efetivamente redistributiva, visando a que as pessoas não sejam discriminadas em função do lugar onde vivem, não pode, pois, prescindir do componente territorial. É a partir dessa constatação que se deveria estabelecer como dever legal - e mesmo constitucional - uma autêntica instrumentação do território que a todos atribua, como direito indiscutível todas aquelas prestações sociais indispensáveis a uma vida decente [...] constituem um dever impostergável da sociedade como um todo e, neste caso, do Estado.
\end{abstract}

Nesse sentido, o Sistema de Garantia de Direitos ${ }^{2}$ da criança e do adolescente deve ser efetivado nos territórios onde ocorrem as violências, a fim de viabilizar o fortalecimento das diversas possibilidades de proteção à criança ao adolescente; principalmente no que tange aos vínculos familiares e comunitários e estabeleça a construção de uma rede articulada de garantia e proteção desse segmento, de modo a respeitar suas particularidades e especificidades, assim como reconhecer suas fragilidades - já que nesses espaços se manifestam em grande escala não somente as situações de violência, mas também outras manifestações da questão social como a pobreza, o desemprego, a escassez de acesso a direitos sociais (habitação, saúde, educação), vínculos familiares fragilizados, entre outros.

Podemos considerar que o território deve ser compreendido com um espaço contraditório, onde se reproduz exclusão e violência, mas também se viabilizam oportunidades, em que as famílias e comunidades se envolvem e se fortalecem num processo coletivo de exercício da cidadania, na busca pela efetivação dos seus direitos. Esse movimento se torna possível graças à "identidade incomum" entre seus membros, permitindo uma visão plural do território, como um espaço que deixa claro suas vulnerabilidades e riscos, no qual seus membros estão expostos, mas que, da mesma forma, permite-nos evidenciar suas potencialidades, a partir de sua cultura, história e

\footnotetext{
${ }^{2}$ O Sistema de Garantia de Direitos se caracteriza por uma interação de espaços, instrumentos e atores no interior de cada um dos eixos, e por uma interação complementar e retroalimentadora entre os três eixos - promoção, vigilância e defesa - em conjunto se articula também a diferentes espaços, instrumentos e atores, formando uma teia de relações entrelaçadas que, de modo ordenado, contribuem para o mesmo fim ou objetivo central definido como garantia de direitos, o mesmo constitui em unidade completa. É o sistema em si mesmo (GARCIA apud SOUZA, 2008, p. 105).
} 
valores, que se configuram em oportunidades, redes de solidariedade, movimentos e organizações sociais que operam na proteção social e na garantia de direitos (KOGA, 2003). O território enquanto um espaço de relações pode ser entendido como: "Um conjunto específico de relações culturais e afetivas entre um grupo e lugares particulares, a uma apropriação simbólica de uma porção do espaço por um determinado grupo, um elemento constitutivo da identidade" (ALBAGLI, 2004, p. 27).

Partindo deste princípio, podemos perceber que o território se coloca como um espaço dinâmico com distintos significados e características específicas, resultantes das variadas dimensões, física, econômica, simbólica e sociopolítica, envolvidas em sua constituição e manutenção, mas principalmente pela atuação do homem, assim como nos coloca Santos (2009, p. 62):

\begin{abstract}
A configuração territorial é dada pelo conjunto formado pelos sistemas naturais existente em um dado país ou numa dada área e pelos acréscimos que os homens superimpuseram a esses sistemas naturais. A configuração territorial não é o espaço, já que sua realidade vem de sua materialidade, enquanto o espaço reúne a materialidade e a vida que anima. A configuração territorial, ou configuração geográfica, tem, pois, uma existência material própria, mas sua existência social, isto é, sua existência real, somente lhe é dada pelos fatos das relações sociais [...] À medida que a história vai fazendo-se, a configuração territorial é dada pelas obras dos homens [...]. Cria-se uma configuração territorial que é cada vez mais o resultado de uma produção histórica.
\end{abstract}

A partir da prática que se concretiza no cotidiano, o território permite a formação da identidade coletiva e individual, sendo criadas relações de amizade, de solidariedade, pois nele são suscitados os sentimentos de pertencimento e enraizamento. De acordo com Maffesoli (apud ALBAGLI, 2004), a sociabilidade necessita de um solo para se enraizar - o que conduz os indivíduos a um passado, a uma memória coletiva, a uma identidade cultural como também a construção de um projeto futuro.

Aqui, o território é considerado como um dos elementos potenciais para uma nova perspectiva redistributiva possível para orientar as políticas públicas. A redistribuição viabilizada pelo acesso às condições de vida instaladas no território onde se vive soma-se aos demais processos redistributivos salariais, fiscais ou tributários, fundiários e das garantias sociais, como a própria reforma fundiária, a reforma fiscal. Parto do pressuposto de que as políticas públicas, ao se restringirem ao estabelecimento prévio de públicos-alvo ou demandas genéricas, apresentam fortes limitações, no que se refere a conseguirem abarcar as desigualdades concretas existentes nos diversos territórios que compõem uma 
cidade, e assim permitir maior efetividade, democratização e conquista de cidadania (KOGA, 2003, p. 20).

Enquanto um espaço de pertencimento, podemos entender que o território nos coloca como parte do seu contexto a proteção social, pois diz respeito às relações interpessoais que se estabelecem entre moradores que se identificam. É a partir do território que o sujeito cria sua identidade pessoal e social, garantindo a sua sobrevivência e proteção. Desta maneira, podem-se utilizar as potencialidades do território para a constituição de poder local que constituam processos emancipatórios de cidadania. Neste sentido, a rede de proteção que apresenta sua característica social e política, pode ser entendida segundo N. Curien (apud SANTOS, 2009) como:

Toda infraestrutura, permitindo o transporte de matéria, de energia ou de informação, e que se inscrevem sobre um território onde se caracteriza pela topologia dos seus pontos de acesso ou pontos terminais, seus arcos de transmissão, seus nós de bifurcação ou de comunicação.

A rede se coloca com um elemento essencial na constituição da garantia e acesso aos direitos sociais, na perspectiva de que a população tenha facilidades ao acessar os serviços, ao invés de dificuldades. Como pode ser destacado na Norma Operacional Básica:

[...] trata-se de identificar os problemas concretos, as potencialidades e as soluções, a partir de recortes territoriais que identifiquem conjuntos populacionais em situações similares, e intervir através das políticas públicas, com o objetivo de alcançar resultados integrados e promover impacto positivo nas condições de vida (BRASIL, 2005, p. 44).

O entendimento do território, dessa forma, vai para além do espaço físico. Ele se coloca como um espaço de relações constituídas, dialeticamente, que pode ser entendido como um instrumento de proteção e superação diante das violências, considerado como "lócus" fundamental na intervenção profissional junto às demandas apresentadas. No entanto, para uma intervenção efetiva, as ações devem proporcionar reflexões e mudanças, com capacidade de exercício de aproximações sucessivas e a revisita à história, ao cotidiano, ao universo cultural da população que vive nesse território, considerando as relações estabelecidas entre seus moradores, no espaço em que se constroem e reconstroem as relações. É no território que se concretizam as relações sociais e que nos permite visualizar as desigualdades que se tornam evidentes entre os cidadãos mediante 
as diferentes condições de vida entre moradores de uma mesma cidade. Assim, como destaca Santos (2007, p. 22):

O território em si não é um conceito. Ele só se torna um conceito útil para a análise social quando ele é considerado a partir do seu uso, a partir do momento em que o pensamos juntamente com aqueles atores que o utilizam. É o uso do território, e não o território em si mesmo, que faz dele o objeto da análise social.

Portanto, coloca-se a necessidade de pensar as ações voltadas ao enfrentamento da violência, mediante a realidade e as manifestações da população inserida neste espaço, o que pressupõe não somente conhecer os riscos, as vulnerabilidades sociais a que estão sujeitos os usuários, mas as potencialidades com que se possa contar para fazer frente a tais situações, de modo que possam ser revertidas com o menor dano pessoal e social possível. Isto significa refletir sobre a dinâmica socioterritorial de modo a entender que para além das necessidades, as pessoas possuem capacidades, que devem ser trabalhadas com vistas à superação das situações vivenciadas, assim como o rompimento dela, na busca pela ampliação da liberdade e das escolhas que podem realizar. Dessa forma, as intervenções diante das situações sociais não podem se restringir à privação social, mas também às potencialidades em se superar a condição atual.

\section{A violência enquanto demanda para o Serviço Social}

A profissionalização do Serviço Social pressupõe a expansão da produção e de relações sociais capitalistas, ou seja, uma especialização do trabalho, parte das relações que fundam a sociedade do capital, que traz no seu verso, a questão social em suas dimensões objetivas e subjetivas, isto é, em seus determinantes estruturais, na produção social, na distribuição desigual dos meios de vida e de trabalho, nas suas objetivações políticas e culturais.

A partir das lutas sociais que romperam com o domínio privado nas relações entre capital e trabalho, extrapola-se a questão social para a esfera pública, exigindo a interferência do Estado no reconhecimento e na legalização de direitos e deveres dos sujeitos sociais por meio da prestação de serviços sociais, cria-se a base que sustenta o mercado de trabalho para o assistente social, em que o Serviço Social deixa de ser um 
mecanismo da distribuição da caridade para se transformar em uma das peças executoras das políticas sociais (IAMAMOTO, 2011).

Este ângulo de análise exige decifrar as multideterminações da questão social no cotidiano da vida social, abrangendo suas manifestações universais, particulares e singulares, a objetividade e a subjetividade, os momentos econômicos, políticos, sociais, éticos e ideoculturais, os quais são a matéria do trabalho do assistente social (ABESS/CEDEPSS, 1996). Sendo assim a questão social pode ser definida por lamamoto e Carvalho (2000, p. 77) como:

\begin{abstract}
A questão social é senão as expressões do processo de formação e desenvolvimento da classe operária e seu ingresso no cenário político da sociedade, exigindo o seu reconhecimento como classe por parte do empresariado e do Estado. É a manifestação, no cotidiano da vida social, da contradição entre o proletariado e a burguesia, a qual passa a exigir outros tipos de intervenção, mas além da caridade e da repressão. O Estado passa a intervir diretamente nas relações entre o empresariado e a classe trabalhadora, estabelecendo não só uma regulamentação jurídica do mercado de trabalho, através da legislação social e trabalhista específicas, mas gerindo a organização e a prestação de serviços sociais, como um novo tipo de enfrentamento da questão social.
\end{abstract}

O Serviço Social tem na questão social a base de sua fundação enquanto especialização do trabalho, em que os assistentes sociais interferem nas relações sociais cotidianas no atendimento às variadas expressões da questão social. Como bem destaca lamamoto (1997, p. 14):

Os assistentes sociais trabalham com a questão social nas suas mais variadas expressões cotidianas, tais como os indivíduos as experimentam no trabalho, na família, na área habitacional, na saúde, na assistência social pública, etc. Questão social que sendo desigualdade é também rebeldia, por envolver sujeitos que vivenciam as desigualdades e a elas resistem e se opõem. É nesta tensão entre produção da desigualdade e produção da rebeldia e da resistência, que trabalham os assistentes sociais, situados neste terreno movido por interesses distintos, aos quais não é possível abstrair ou deles fugir porque tecem a vida em sociedade.

Assim, os assistentes sociais trabalham com as múltiplas expressões da questão social tal como se expressam na vida dos indivíduos sociais, a partir de políticas sociais e na forma de organização da sociedade civil na luta por direitos, podendo ser entendido como um profissional: 
[...] que convive diariamente com as mais amplas expressões da questão social, matéria-prima de seu trabalho. Confronta-se com as manifestações mais dramáticas dos processos sociais aos níveis dos indivíduos sociais, seja em sua vida individual, seja em sua vida coletiva (ABESS/CEDEPSS, 1996, p. 154-155).

Desse modo, consideremos a violência como uma expressão da questão social que pode ser entendida como "o conjunto das expressões das desigualdades da sociedade capitalista madura" (AZAMBUJA, 2011, p. 122). Reflete o projeto político, social e econômico hegemônico, os quais a sociedade esta inserida e que atualmente se traduz numa sociedade extremamente excludente. Assim, podemos ressaltar a relevância da violência contra crianças e adolescentes no cenário atual, sendo este considerado um fenômeno complexo de múltiplas determinações, podendo ser caracterizado sob diversos enfoques, entre os quais citemos o autor Michaud (2001, p. 10-11):

Há violência quando, numa situação de interação, um ou vários atores agem de maneira direta ou indireta, maciça ou esparsa, causando danos a uma ou várias pessoas em graus variáveis, seja em sua integridade física, seja em sua integridade moral, em suas posses, ou em suas participações simbólicas e culturais.

Sendo assim, considerando as diversas formas de violência como manifestações que atingem, ferem e dilaceram os direitos humanos ${ }^{3}$ mais básicos previstos nos mais diversos dispositivos legais, que visam assegurar a paz e a sobrevivência humana, podemos destacar que:

[...] onde não houver respeito pela vida e pela integridade física e moral do ser humano, onde as condições mínimas para uma existência digna não forem asseguradas, onde não houver limitação do poder, enfim, onde a liberdade e a autonomia, a igualdade (em direitos e dignidade) e os direitos fundamentais não forem reconhecidos e minimante assegurados, não haverá espaço para a dignidade da pessoa humana e esta (a pessoa), por sua vez poderá não passar de mero objeto de arbítrio e injustiças (SARLET, 2001, p. 59).

Diante desta configuração a respeito da violência aqui abordada é que percebemos a necessidade de serviços especializados de caráter continuado para a família e os

\footnotetext{
${ }^{3}$ A Declaração Universal dos Direitos Humanos da Organização das Nações Unidas afirma que todos os seres humanos nascem livres e iguais em dignidade e em direitos, dotados de razão e de consciência e devem agir uns para com os outros em espírito de fraternidade.
} 
indivíduos que estejam em situação de risco pessoal e social, por violação de direitos, que apresentem enquanto objetivo fortalecer os vínculos e reconstruir os laços familiares e/ou comunitários, a fim de que a situação vivenciada seja superada.

Neste sentido, coloca-se aos profissionais que trabalham junto a esta demanda um grande desafio diante da busca pela superação de tal situação e ao assistente social em especial, à medida que se coloca como um profissional capaz de desvelar a realidade na qual essas expressões da questão social se manifestam como destaca lamamoto (2000, p. 28):

[...] apreender a questão social é também captar as múltiplas formas de pressão social, de inversão e de re-inversão da vida, construídas no cotidiano, pois é no presente que estão sendo recriadas as novas formas de viver, que apontam um futuro que está sendo germinado.

Para tanto, o assistente social deve se voltar à postura crítica, política, comprometido com o constante aprimoramento intelectual e compromisso ético profissional, rompendo com o teoricismo, bem como com "o fazer por fazer", compreendendo que prática e teoria são condições que requerem a apropriação uma da outra.

Neste sentido, é que se coloca aos profissionais a busca contínua pelo conhecimento, principalmente diante de demandas tão complexas quanto a violência, ou seja, uma capacitação que implica a revisão permanente de conceitos e valores, de modo a proporcionar a quebra de paradigmas e a construção de uma nova realidade.

Portanto, diante de tais questões que se colocam na relação entre o conhecimento e a ação é que se faz necessário que o assistente social, bem como os demais profissionais e os serviços que lidam com as expressões da violência, insiram-se nesta realidade de modo a compreendê-la e, assim, buscar alternativas de transformações possíveis e necessárias, bem como ações que promovam o fortalecimento dos vínculos e o rompimento e superação das situações de violências vivenciadas.

\section{Considerações finais}

Considerando as questões levantadas ao longo do trabalho, podemos perceber as implicações das relações capitalistas vigentes, ou seja, o modo de organização da sociedade que se dá a partir das disparidades sociais num processo de apropriação de uma classe pela 
outra. Neste processo, podemos adentrar ao grande fosso de desigualdade existente entre as classes, resultando na questão social e suas expressões, como a violência contra crianças e adolescentes.

Dessa forma, ressaltamos a importância de se conhecer, para além do aparente, a cultura, crença, valores etc., assim como o contexto sócio-histórico que provoca e influencia determinadas situações que envolvem diretamente a população - a violência que se coloca como uma destas manifestações, a partir de uma relação de força e autoridade sobre o outro, na perspectiva da negação de valores.

Destacamos o território como o espaço que nos permite compreender não somente a realidade concreta, mas as relações interpessoais, de modo a evidenciarmos sua capacidade de transformação - enquanto um processo coletivo na concretização da cidadania - assim como suas fragilidades, na medida em que expressa desigualdades. No território, encontramos a violência e a exclusão, mas também encontramos potencialidades, por meio de diferentes formas de organização das comunidades que apresentam vínculos de pertencimento e que se reconhecem. No mesmo movimento, o território é entendido como instrumento imprescindível na formulação e implantação de políticas sociais, na perspectiva redistributiva dos direitos e garantias sociais. É desse modo que se apreende a importância da organização como espaço político no processo de transformação. Neste sentido, o papel das redes sociais que se faz presente no território torna-se um instrumento de garantia de acesso e efetividade dos direitos sociais, mediado pela organização e articulação dos sujeitos sociais, respeitando as particularidades e especificidades de cada espaço.

Portanto, a violência enquanto uma expressão da questão social traz embutida na sua configuração a formatação da sociedade vigente, influindo diretamente nas relações sociais cotidianas. Daí a relevância do território, o que nos permite uma leitura mais próxima desse cotidiano vivido pelas populações, colocando como um instrumento de grande potencial na proteção e superação das violências. Permite ainda que as ações e as políticas sociais se direcionem para a realidade do seu público-alvo, de modo que tais medidas ganhem efetividade e garantam a participação de todos a partir do sentimento de pertencimento do espaço onde vivem, assegurando não somente a inserção e acesso dos 
direitos no território, mas, e acima de tudo, que se identifiquem como parte constituinte deste processo.

Portanto, podemos perceber que as expressões da questão social decorrem das mais variadas formas de relações estabelecidas e presentes na sociedade, e traz enquanto parte constituinte de sua formação, o modo de produção capitalista a partir das relações de desigualdade. Sendo assim é que se coloca a necessidade de se pensar em intervenção qualificada junto a estas expressões, mediante a implantação e formulação de políticas públicas cada vez mais próximas da realidade social, isto é, de seus territórios. Nesta perspectiva, cabe aos diferentes profissionais uma atuação efetiva capaz de oferecer respostas concretas, e que atendam às reais necessidades da população.

\section{Referências}

ALBAGLI, S. Território e territorialidade. In: LAGES, V.; BRAGA, C.; MORELLI, G. (Org.). Territórios em movimento: cultura e identidade como estratégia de inserção competitiva. Rio de Janeiro: Relume Dumará; Brasília: SEBRAE, 2004. p. 25-69.

ABESS/CEDEPSS. Proposta básica para o projeto de formação profissional. Serviço Social \& Sociedade: O Serviço Social no século XXI, São Paulo, ano XVII, n. 50, p. 143-171, abr. 1996.

AZAMBUJA, M. R. F. Inquirição da criança vítima de violência sexual: proteção ou violação de direitos? Porto Alegre: Livraria do Advogado, 2011.

AZEVEDO, M. A.; GUERRA, V. N. A. Crianças vitimizadas: a síndrome do pequeno poder. São Paulo: Iglu, 1989.

. Infância e violência fatal em familia: primeiras aproximações ao nível de Brasil. São Paulo: Iglu, 1998.

. Mania de bater: a punição corporal doméstica de crianças e adolescentes no Brasil. São Paulo: Iglu, 2001.

BRASIL. Estatuto da Criança e do Adolescente. São Paulo: Cortez, 1990.

. Ministério de Desenvolvimento Social e Combate à Fome. Política Nacional de Assistência Social. Brasília, 2004.

Ministério do Desenvolvimento Social e Combate a Fome. Norma Operacional Básica NOB/SUAS. Brasília, 2005.

CASTEL, R. Les métamorphoses de la question sociale: une chronique du salariat. Paris, Fayard, 1995. 
COUTINHO, C. N. Contra a corrente: ensaios sobre democracia e socialismo. São Paulo: Cortez, 2000.

FERNANDES, F. A revolução burguesa no Brasil: ensaios de interpretação sociológica. Rio de Janeiro: Zahar, 1975.

GUERRA, V. N. A. Violência de pais contra filhos: a tragédia revisitada. 3. ed. São Paulo: Cortez, 1998.

IAMAMOTO, M. V. O serviço social na contemporaneidade: dimensões históricas, teóricas e ético-políticas. Fortaleza: CRESS-CE, 1997. Debate n. 6.

. O serviço social na contemporaneidade: trabalho e formação profissional. 7. ed. São Paulo: Cortez, 2004.

. O serviço social na contemporaneidade: trabalho e formação profissional. 3. ed. São Paulo: Cortez, 2000.

Serviço social em tempo de capital fetiche: capital financeiro, trabalho e questão social. São Paulo: Cortez, 2011.

IAMAMOTO, Marilda; CARVALHO, Raul de. Relações sociais e Serviço Social no Brasil: esboço de uma interpretação histórico-metodológica. 13. ed. São Paulo: Cortez; Lima (Peru): Celats, 2000.

IANNI, O. A questão social. In: . A ideia do Brasil moderno. São Paulo: Brasiliense, 1992.

JAGUARIBE, H. Brasil 2000: para um pacto social. Rio de Janeiro: Paz e Terra, 1986.

KOGA, D. Medidas de cidades: entre territórios de vida e territórios vividos. São Paulo: Cortez, 2003.

MICHAUD, Y. A violência. São Paulo: Ática, 2001.

MINAYO, M.C.S. O desafio do conhecimento: pesquisa qualitativa em saúde. São Paulo/Rio de Janeiro: Hucitec-Abrasco, 1994.

SANTOS, M. O espaço do cidadão. São Paulo: Ed. Universidade de São Paulo, 2007. . A natureza do espaço: técnica e tempo, razão e emoção. 4. ed. São Paulo. Ed. Universidade de São Paulo, 2009. (Coleção Milton Santos, 1).

SARLET, I. Dignidade da pessoa humana e direitos fundamentais na Constituição Federal de 1988. Porto Alegre: Livraria do Advogado, 2001.

SOUZA, J. C. A afetividade dos direitos da criança e do adolescente. São Paulo: Pillares, 2008. 
TELES, M. A. A.; MELO, M. O que é violência contra a mulher. São Paulo: Brasiliense, 2003.

TELLES, V. S. Questão social, afinal do que se trata? São Paulo em Perspectiva, São Paulo, v. 10, n. 4, p. 85-95, 1996.

WANDERLEY, L. E. A questão social no contexto da globalização: o caso latino-americano e caribenho. Os enigmas do social. In: WANDERLEY, L. E. (Org.). Desigualdade e a questão social. 2. ed. São Paulo: EDUCA, 2000.

Recebido em: 03/04/2014

Aprovado em: $12 / 08 / 2014$ 